\title{
10. Why and how media storms affect front-line workers
}

\author{
Scandalized Danish crèches as an example. \\ Pernille Carlsson and Christian Elmelund-Prcestekcer
}

\author{
Vasterman, Peter (ed.), From Media Hype to Twitter Storm. News Explo- \\ sions and Their Impact on Issues, Crises, and Public Opinion. Amsterdam \\ University Press, 2018 \\ DOI: $10.5117 / 9789462982178 / \mathrm{CHO} 5$
}

\begin{abstract}
Although media scholars often claim that news coverage impacts perceptions, and scholars of public administration stress the importance of public agencies' image in case of media storms, no one has studied if and how such storms affect public bureaucracy or, more specifically, front-line workers. We fill this lacuna by reviewing theoretical arguments for why and how media storms might be consequential at the street level of public services. We complement the arguments with an empirical illustration examining how the experience of pre-school teachers increased crosscutting pressures in the aftermath of a media storm about the quality of Danish crèches. In sum, we argue that scholars of media effects and public administration will benefit from bridging the divide between the two disciplines.
\end{abstract}

Keywords: front-line workers, media storm, media effects

\section{Introduction}

Modern democracies are mediatized, which means that societal actors have adopted the media's logic and that communicative considerations are an integrated part of politics (Hjarvard, 2013; Mazzoleni \& Schulz, 1999). Consequently, a vast number of approaches has been employed in the study of media effects (Bennett \& Iyengar, 2008; Neuman \& Guggenheim, 2011); but while many studies analyse direct and conditioned effects on public opinion and policymaking (Potter, 2013; Vliegenthart \& Walgrave, 
2011; Weaver et al., 2004), we know very little about the media's possible effects on the implementation of public policy. This lacuna is surprising given the classical argument that street-level bureaucrats are the ultimate policymakers (Lipsky, 1980): if the media prompts bureaucrats and front-line workers to act differently than they would otherwise have done - which, we argue, is a likely scenario - the media have uncharted societal consequences.

There is no doubt that the public administration has been mediatized over the past decades. Ample scholarly evidence illuminates the ways in which public institutions have adapted to the media's logic in order to brand themselves, set the public agenda, or execute effective crisis communication (Eshuis \& Klijn, 2012; Schillemans, 2012; Thorbjornsrud et al., 2014). Other strains of the literature investigate how public agencies - and individual employees at various levels in these organizations - exercise a range of blame avoidance strategies to protect their organizational reputation in times of intense negative media coverage (e.g. Carpenter \& Krause, 2012; Hood, 2010). This wealth of studies investigates the relation between public administration and the media, but most scholars study how public agencies can utilize the media or affect media content to ensure certain organizational goals. We know surprisingly little about the reverse relationship, i.e. how (critical) media coverage affects public agencies, their procedures, and their employees (for a rare exception see Wilmar et al., 2014).

In this chapter, we take the latter approach and discussion how and why media storms might affect the work-life of front-line workers. Evidence holds that media storms affect mass political behaviour (Trumbo, 2012) and, to some degree, public policymaking; but, at the same time, it is suggested that such storms 'affect decisions or procedures in the (local) bureaucracy [but] the question of any possible effects on the administrative level [is left] open to future studies' (Elmelund-Præstekær \& Wien, 2008: 250).

Despite the fact that scholars of political communication predominantly study media effects at the mass and (political) elite level, it is highly plausible that the media is also influential at the street level of public administration. Unlike elected politicians, front-line workers have scarce resources and little experience with the media scrutiny of their work (Hood, 2010: 31). Moreover, existing studies find 'remarkably strong emotional and social effects of negative press reports on the subjects of such articles' (Kepplinger \& Glaab, 2007:352; see also Wilmar et al., 2014), so, even though individual public employees might not be criticized in the news, one might suspect that critical media coverage of their work and/or institution affects them negatively. 
We believe that both the public administration literature and the field of political communication can benefit from joining theoretical and empirical forces. The two have developed in isolation (Korthagen \& Klijn, 2014), but by combining them it will be possible to gain a deeper understanding of the factors that shape public service delivery as well as a deeper understanding of the media's societal role. Apart from providing a general argument as to why media storms might be influential at the street level (section 1), we also theoretically discuss how media coverage more precisely is expected to affect front-line workers (section 2). In addition, we provide an empirical illustration of our theoretical arguments as we explore whether a media storm about Danish crèches affected pre-school teachers working there and, if so, how (section 3). Following our theoretical propositions, we study pre-school teachers' individual thoughts about the media storm and we explore the relation between the pre-school teachers and a) intermediate management and b) parents. In the final section (4), we conclude the analysis and consider the future promise of a happy marriage between political communication and public administration.

\section{Why would media storms affect front-line workers?}

Defined broadly as 'an explosive increase in news coverage to a specific item (event or issue) constituting a substantial share of the total news agenda during a certain time' (Boydstun et al., 2014: 6), a media storm has the potential to blow over all kinds of societal issues; not only in relation to e.g. public crisis management in natural disasters like the Hurricane Catrina, but also in relation to man-made scandal like political and administrative power abuse, and self-referential media coverage without an underlying real-world problem. Common to the various types of storms is that they often relate to the implementation, rather than the formulation of public policy because they are triggered by concrete problems or discoveries - not by governments promoting a legislative bill or a political solution to an abstract societal problem. In effect, media storms often focus on alleged implementation failures, e.g. the police's failure to combat street crime (Vasterman, 2005) or carers' failure to take care of the elderly (Elmelund-Præstekær \& Wien, 2008). The focus on implementation failure might be one reason why existing studies do not find policy effects of the analysed media storms: in their study of five media storms about the quality of Danish public care of the elderly, Elmelund-Præstekær and Wien (2008: 262), for instance, conclude that the storms 'did not bring about new policies, increases of budgets, dismissal 
of ministers, changing laws or other types of regulations'. Opposition MPs might ask questions to the responsible minister and the government might order reports and evaluations, but such activities remain symbolic. In general, an absence of effects on policymaking is not surprising if storms pinpoint problems in the implementation of a given public policy: why should politicians alter (national) legislation if a problem arises from (local) implementation errors? In such cases, it is more likely that possible effects of media storms are to be found at the street level. We now consider in more detail just how a media storm can be expected to affect front-line workers.

\section{How could media storms affect front-line workers?}

Policy implementation is a complex phenomenon shaped by multiple and rather diverse factors. In an effort to synthesize an overall, integrated model, Winter (1994) highlights six major factors: 1) policy design; 2) implementing organization; 3) management; 4) target group; 5) individual discretion on behalf of the street-level bureaucrats; and 6) external environment. In our theoretical model, we do not include the first two factors as they are considered constants during a specific media storm. Below, we will discuss the latter four factors.

According to Lipsky (1980:3), street-level bureaucrats (or front-line workers) are 'public service workers who interact directly with citizens in the course of their job, and who have substantial discretion in the execution of their work'. Such workers are situated at the bottom of a hierarchical system, ultimately controlled by publicly elected officials. Moreover, they have limited resources at their disposal and these characteristics induce cross-cutting pressure because higher echelons in the organization may demand different, better and more services, which cannot always be realized with the resources allocated. This pressure is known to induce a sense of inadequacy at the street level, and it is a potential trigger of work-related stress for the individual worker (Kaufmann \& Kaufmann, 2008). Not only do front-line workers have political principals and intermediate managers, they also face the target group on a daily basis - and this group is as likely as their superiors to demand more and better service (Lipsky, 1980), which only increases the pressure.

The cross-cutting pressure on the individual front-line worker is likely to increase when the organization or services is intensively discussed in the mass media. The reason is straightforward; mass media attention is guided by problems, conflicts, misconduct, and scandals (e.g. Galtung \& Ruge, 1965). Consequently, public service institutions and agents are predominantly in 


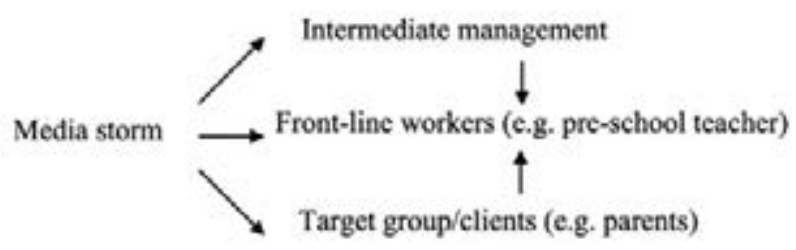

Figure 10.1. A simple model of how a media storm affects front-line workers

the spotlight when something is wrong and needs to be fixed - and such a fix most likely involves more, better, or at least different efforts on behalf of the front-line worker. The negativity bias of the media is empirically substantiated by a study of the framing of public organizations in Swedish and Australian media, which found 'more negative than positive news stories and [that] the negative stories tend to stick, for instance by sparking off numerous follow-up stories' (Schillemans \& Jacobs, 2014:152). Moreover, positive - or more precisely, neutral - news was predominantly routine news about planned events or official statistical information promoted by public agencies themselves and not by journalists.

Given this background, we suggest that the cross-cutting pressure increases in the wake of a media storm. To develop a deeper understanding of this interaction, we aim to figure out exactly why the pressure intensifies. Events in the environment need to be adopted by actors in the implementation system and drawing on the above cited works, Figure 10.1 provides a simplistic illustration of how the different actors potentially respond to the environment (i.e. a media storm) and induce pressure on the front-line worker. First, the media storm might affect the worker directly. Second and third, the media storm may affect the worker indirectly by prompting either the managers or the target group to demand more or better efforts. We discuss each of the three possibilities in greater detail below.

\section{Does a media storm affect the front-line workers directly?}

A classical argument is that cross-cutting pressures and diverging expectations prompt front-line workers to activate coping strategies. The list of such strategies is long and includes, e.g. limitation of service demand, creaming, standardization, and goal displacement. These expectations derive from rationalistic assumptions about human nature and can be summed up in two overall strategies, i.e. shirking and sabotage (Brehm \& Gates, 1997). 
The underlying rationalistic concept of personal interest does not capture, however, the entirety of interest guiding workers at the street level in the public sector. Brehm \& Gates (1997) argue that front-line workers are not solely driven by higher salaries and less work, but also by functional and solidary interests. The functional interest is proven to be particularly strong, and it prompts the individual to work rather than shirk, because the nature and content of the job represents an intrinsic value. The social interest arises because one's efforts at the job provide social acceptance and a collegial community. In sum, the complex interest configuration may prompt frontline workers to rethink their work in order to optimize performance when a media critically assesses the state of their field of work. In short, we expect that:

E1: Front-line workers experience increased cross-cutting pressure during a media storm in their field, because the storm conflicts with their functional and solidary interests

\section{Does a media storm affect the front-line worker indirectly through managers?}

It is well-established that the large degree of professional discretion makes front-line workers difficult to lead - managers simply do not know exactly what problems and solutions exist, nor do they know how the subordinates behave (May \& Winter, 2009; Riccucci, 2005; Sandfort, 2000). Brehm \& Gates (1997: 27) conclude that management has little effect on the managed, and that 'effective supervision depends on the characteristics of subordinates, not on the characteristics of their supervision'. Thus, front-line works may (only) be led when instructions resonate with the functional and solidary interests of the workers themselves. On this basis, we do not expect that intermediate management increases the cross-cutting pressure on the front-line workers during a media storm. Our second expectation thus reads:

E2: Front-line workers do not experience an increased demand on behalf of managers during a media storm in their field

Does a media storm affect the front-line worker indirectly through the target group?

Finally, our model suggests that a media storm may affect the front-line worker indirectly through the target group. Studies indicate that the target 
group is capable of affecting public service employees, e.g. by asking critical questions in the course of the everyday interaction (Nielsen, 2006). This interaction is moderated by the frequency of interaction and the resources of the target group (Nielsen, 2002). First, since frequent interaction decreases the information asymmetry - the target groups simply have more insight into the working of front-line workers - it increases the chances to open a dialogue between the two. Second, it takes resources, i.e. time, engagement, and a minimum of knowledge about the public service in question, to confront professional front-line workers. On this basis, our final expectation reads:

E3: Front-line workers experience increased cross-cutting pressure during a media storm in their field because the target group criticizes the status quo

\section{An empirical illustration}

To empirically illustrate the viability of our central argument, we conduct a case study of a media storm about the quality of Danish crèches (vuggestuer). Almost ninety per cent of Danish children are enrolled in crèches at the age of one year (www.dst.dk). At the age of three years, the children move to kindergartens (børnehave) where pre-school education is continued until primary school begins at the age of six. All these institutions are public, and the few private ones rely on public subsidies.

\section{The case}

The media storm was triggered by one of the major newspapers, Berlingske. A journalist quoted $\mathrm{PhD}$ student Ole Henrik Hansen in a print article on 29 April 2012. The quote was from his speech at a major convention for pedagogical professionals, where he presented preliminary conclusions of his research. Ole Henrik Hansen accused Danish crèches of being 'free marihuana and complimentary drinking-chocolate institutions' where children are left to themselves in 'loveless storage'. He criticized the pre-school teachers of confusing the concept of 'free play' with absence of adults and structured daily activities. To demonstrate the point, Berlingske mentioned a video clip that later the same day was aired by the national television news broadcaster $T V_{2}$. In the video, a fourteen-month-old boy picks up a bus from the toy box and hides behind an adult to escape a bus theft about to be committed by an older boy. Then, another child starts crying and the small boy moves in 
front of the adult - according to Ole Henrik Hansen he tries to say, 'I know you need to go but will you please protect me and my bus?' Without looking at the boy, the adult pushes him aside and the older boy snatches the bus.

Ole Henrik Hansen argues that the biggest problem is that the boy does not react to the bus theft; he simply acknowledges the loss and leaves. The situation teaches the boy that he is the kind of guy that toys are taken from because he is not strong enough to protect it or able to attract the possible helper's (the adult's) attention. The result, according to Ole Henrik Hansen, is that children in similar situations shut down emotionally and that their brain development might be negatively affected. Moreover, Ole Henrik Hansen argues that better budgets will not solve the problem - it primarily has to do with the attitudes of the pre-school teachers that need to spend more time with the kids instead of gossiping with each other. Pre-school teachers also need to provide a structured environment in which the physically and psychically strong kids do not dominate the weaker.

After the trigger article in Berlingske, other media followed suit, and the next day Ole Henrik Hansen's name appeared in more than 100 news products across the Danish media landscape. Thus, our case clearly has the characteristics of a media storm when defined as 'an explosive increase in news coverage to a specific item (event or issue) constituting a substantial share of the total news agenda during a certain time' (Boydstun et al., 2014:6).

\section{Data and method}

We conducted seven qualitative interviews with pre-school teachers in seven crèches situated within Odense, a major Danish municipality. Since the data that triggered the media storm derives from Copenhagen, it is important for us to study the possible effects in a different city; thus, we are able to explore general effects in the entire pre-school sector and not merely local effects. Danish crèches are run by the municipalities and, consequently, management, organization, and economic viability vary across crèches in different municipalities. To eliminate possible effects of such non-media factors, we focus on one municipality only. Also, we chose a relatively large one to ensure a certain amount of within-case variation. In this regard, it is important that we include pre-school teachers from different crèches because the commitment of (and thus the pressure induced by) the parents may vary between crèches - parents in wealthy and well-educated areas of the city are likely to engage more in discussions about the pedagogical service than parents from areas with lower socio-economic status. 


\begin{tabular}{|c|c|c|c|c|}
\hline Interviewee & Age & $\begin{array}{l}\text { Graduation } \\
\text { year }\end{array}$ & Education & $\begin{array}{l}\text { Size of } \\
\text { institution* }\end{array}$ \\
\hline PA & 37 & 1999 & $\begin{array}{l}\text { BA in social education, } \\
\text { language councilor, Diploma } \\
\text { in social education }\end{array}$ & $30(0)$ \\
\hline PB & 53 & 1983 & BA in social education & $24(23)$ \\
\hline PC & 40 & 2002 & BA in social education & $12(59)$ \\
\hline PD & 57 & 1977 & BA in social education & $31(55)$ \\
\hline PE & 43 & 1996 & BA in social education & $26(0)$ \\
\hline PF & 59 & 1988 & BA in social education & $11(42)$ \\
\hline PG & 57 & 1982 & $\begin{array}{l}\text { BA in social education, } \\
\text { language councilor }\end{array}$ & $22(33)$ \\
\hline
\end{tabular}

Table 10.1. Overview of interviewees

* Some child houses are so-called combined houses including both a crèche and a kindergarten. The size of the latter is indicated in parenthesis.

Since we are interested in learning about perceived cross-cutting pressures of the pre-school teachers, we opt for semi-structured qualitative interviews. This type of interviews allows us to a) focus on the specific aspects of everyday work-life that we consider important due to our theoretical discussion, and b) to explore aspects, thoughts, and feelings among the pre-school teachers that we did not consider a priori. Semi-structured interviews thus allow us to combine theory-driven expectations about which aspects of work-life are affected by a media storm and an explorative investigation of how these aspects are affected. To structure the interviews, we compiled an interview guide based on the theoretical discussion above. The interview guide as well as a full transcript (in Danish) of the interviews is available upon request.

The municipality of Odense is divided into four districts, and the city has a total of twenty-seven crèches. These twenty-seven crèches are umbrella organizations, and each of them consists of four to seven so-called child houses, which are the actual organizational unit to which children are admitted. To recruit interviewees, we established contact with leaders of several of the twenty-seven crèches, making sure that we included some from all four districts. We relied on those leaders to pick pre-school teachers employed in different child houses - we ensured that we did not talk to more than one person per house. We acknowledge that this procedure might induce a leadership bias, but we were not allowed to contact individual pre-school teachers directly. Moreover, we promised the interviewees anonymity to make sure that no one would worry about possible controversial 
statements. We found that seven interviews provided a rich and saturated (Kvale, 2004: 109) empirical material and thus we did not go on to conduct any more. Table 10.1 provides an overview of the interviews conducted.

\section{Analysis}

We began our interviews by asking general questions about the daily work in the crèches and especially about cross-cutting pressure and the degree of individual professional discretion felt by the pre-school teachers. We did so to get the conversation going and to establish a base line to which we can compare the special situation arising during the media storm. It is evident that our interviewees feel a large degree of professional discretion and that they are able to structure their work and prioritize between different goals - for example, one interviewee 'can suggest activities myself - a trip out of the house, down in the basement for gym [...]. For example, we saw a course in baby signs. That could be amazing so we decided to enrol. When we came back we all agreed that we should do this and we've used it ever since' (PA). However, the professional discretion operates within certain boundaries. Economic limitations and bureaucratic demands play a central role and prevent pre-school teachers from performing at their best. One states that demands 'from above in terms of cutbacks [...] and more and more documentation [entail that] one does not have the opportunity to do the job as good as one would like' (PB). Also, all interviewees mention the public awareness of their work, which reassures us that our theoretical model pinpoints the most central elements regarding the creation of cross-cutting pressures, namely, pre-school teachers' professional ethos, their managers, and the parents.

When evaluating the possible impact of the media storm, a prerequisite is that our interviewees are aware of it. It is indeed the case. We asked an open question about whether they could think of something in their organizational environment or in the public debate that imposed special challenges on their ability to do their job as they would like. Four out of seven interviewees pointed to the media storm in question as such an event. We showed the storm's trigger article to the remaining three, and they all immediately recalled the content of the storm: 'I remember that story. Wasn't it the one where some video showed that a pre-school teacher did not see a child?' (PD). In conclusion, we suggest that the media storm was salient to all interviewees. We now turn to the central question; did the storm intensify pre-existing cross-cutting pressures and why did it possibly do so? 
Expectation 1: The media storm's direct impact on pre-school teachers. We find empirical support for our expectation that the front-line works - in our case, pre-school teachers - experience increased cross-cutting pressure during the media storm because it conflicts with their functional and solidary interests.

Initially, one might conclude that the interviewees simply rejected the critical content of the media storm as several interviewees appeared rather confident in their daily practices. One said that, in her team, they said to one another that 'we don't take this one to the heart, right? Because we know that we do a great job' (PG). But still, the same individual reports to be 'hurt on my professionalism when I think I perform and work like a beast and the result is criticism [...] Then you get hurt - what is it they want?' Such a statement shows that the media storm is not simply ignored - rather, it conflicts with the functional as well as the solidary preferences of the pre-school teacher: she displays doubt about which expectations she is supposed to meet while she intends to do her best. In the end, the media storm made her reflect over her practice: 'of course some things also sank in. The thing he said about how we should organize better because we are merely firefighting and stuff. We reflected over that and said we must organize our work better and take a stand and be more aware of the way we do things'(PG). In fact, the media storm did not only prompt an intellectual reflection, but also actual action: 'we tried to make a new structure in the house, but it didn't work out. But [today] we are much more conscious and we plan our work. We didn't do that so much before' (PG). In sum, the evidence suggests that the pre-school teacher's professional interest in doing a good job conflicts with the criticism levelled in the media storm.

The media storm had a similar constructive effect on several other interviewees. They describe the public debate as a positive and relevant contribution that provides an opportunity for reflection: 'in some way or another I kind of like that somebody stirs things up a bit, asks questions and has focus on us. It makes me think as well; does he have a point? What is my stand in this regard? Is there anything I can do differently? We are captured by a zoom lens and thus one gets a sharper pair of glasses to look at one self in the company of the kids' (PC). One of the other pre-school teachers said that 'such episodes are actually great to watch' (PF) because it makes certain issues salient; in particular, it prompted her to pay special attention to the less self-promoting children. This problem was related to the physical layout of the crèche and the demand for multiple rooms that allow pre-school teachers to split the children up into smaller groups. Inspired by the media storm, she even 'had a male social-educator assistant, we had 
at the time, to install a table in the bathroom so we could go out there and do something with the bigger kids and shield them in their play every now and then' (PF).

While several interviewees thus took action, and changed their practice or institution in order to achieve a better balance between their functional preference and reality, others guarded themselves by underlining that the problems pinpointed in the media storm were not apparent in their practice or institution. But still most of these interviewees acknowledged that the media storm 'definitely made us more aware of the benefit of smaller groups' (PE). One interviewee, however, seems rather unaffected: 'we are sure that all kids are seen, hugged and that everybody gets something from each of us. We don't feel affected be the media storm [...] This is because we work a lot with these issues [...] I can say that because we do a lot to make sure that the children come first' (PA). The media storm simply did not apply to her because the problems discussed in the storm were already solved or at least handled within her institution. We suggest that this particular interviewee did not react to the storm because it did not conflict with her functional preference. She happens to be the only interviewee who completed higher education (a social education degree), and we suggest that this may reinforce professional self-assurance and thus function as a shield against media storms - an issue we return to in the concluding section.

For now, our general conclusion is that the media storm increased the cross-cutting pressure imposed on the individual front-line worker, but it also made workers adjust their practice in a constructive way, guided by professional knowledge.

Expectation 2: The media storm's indirect impact on pre-school teachers via management. Our overall conclusion is that management seldom acts in ways that reinforce the cross-cutting pressure on the pre-school teachers. Thus, we find at least some empirical support for the expectation that front-line workers do not feel the heat from their managers during the media storm.

Only one interviewee experienced management intervention, and she pointed to a new way of organizing age groups: 'I imagine that it is a consequence of that [the media storm] because our manager said - when I asked why we have to change something that works - that we should not be the last ones riding the wave. At that point I just felt, well, poor argument, right?' (PE). The instance made the pre-school teacher realize that she was part of a hierarchical structure that forced her to adhere to new rules that conflicted with her conception of best practice. Thus, the media storm 
indirectly intensified the cross-cutting pressure in the interviewee's daily work. This pressure is especially evident because the new organization made the interviewee insecure about what she could do differently: 'at any rate, I think they should have used more professional arguments in favour of the reorganization before it was implemented. I had a hard time figuring out what I should act on. What is it I must do differently? What is expected of me?' (PE). As a note of caution, we should underline that we cannot be certain that the reorganization in fact was a consequence of the media storm - it is merely assumed by the interviewee.

None of the remaining interviewees mentioned any management interference; to the contrary, some report that their manager was completely on their side: 'Our daily manager doesn't think that things are as he [Ole Henrik Hansen] described them' (PF). Other interviews delivered clear-cut answers like: 'no, I don't think that was the case' (PC) when we directly asked them if managers had mentioned the media storm in relation to local performance. It is, however, important to remember that some of the institutions are combined institutions, meaning that that the crèche is only a part of the entire institution. Managers thus had multiple focus points that might distract their attention. For instance, one interviewee said that her local manager was 'not a crèche kind of guy so he didn't really go into it' (PB). Another reason why intermediate management was absent in street-level discussions about the media storm was the simple fact that one of the houses was in-between managers at the time of the media storm.

In sum, only one pre-school teacher reported that management took action in the aftermath of the media storm. The rest either reported that managers did not say or do anything, or reported that local managers were on the employees' side during the storm. Against this backdrop, we are confident in concluding that the empirical material supports our theoretical expectation, namely that media storms do not affect front-line workers indirectly via their managers.

Expectation 3: The media storm's indirect impact on pre-school teachers via parents. We now turn to the second indirect route for a possible impact of the media storm as we explore how pre-school teachers perceive parents' reactions to the storm. Overall, the empirical evidence does not support our expectation that media storms affect front-line workers this way, since parents generally did not level criticism against either individual pre-school teachers, or their local institution.

Only one out of our seven interviewees mention the issue of critical parents. This particular pre-school teacher underlines that parents were 
sometimes dissatisfied and questioned the commitment of her and her colleges as well as specific things they do. Parents indeed affected her work-life, and she reports spending time talking to them explaining why things are done in certain ways. Besides this general picture, she also told that the amount of worried parents increased during the media storm: 'we had many parents who came to asked about their kids; how they thrive. They also had a hard time leaving the child - also because he [Ole Henrik Hansen] specifically said something about, can't remember exactly what, but about daddy and mommy abandoning the children down here and that it was a kind of child neglect' (PC). The parents did not demand anything new or different, however, the interviewee merely thinks 'that they needed to be reassured that everything was okay and that we took care of their children' (PC). In short, the media storm prompted some parents to ask questions they would not otherwise have asked - at least not at that particular point in time. Such questions did not alter anything in the everyday practice of the crèche, but they might have added to the cross-cutting pressure on the specific pre-school teacher.

The remaining interviewees did not experience critical or concerned parents. In fact, several pre-school teachers had the opposite experience as they told about supportive parents displaying a great deal of confidence in the local institution and the pre-school teachers they knew personally: 'our parents said that he [Ole Henrik Hansen] should come here and see for himself, because it's just not that way here! [...] We very much feel that they have confidence in us, that they think we do our job well and that we are there for their children' (PE). The general impression is that parents had no quarrels with the pre-school teachers and their local institution. Since 'parents of today are demanding; they come in with sick kids and complain if you call them to tell that the kid has been crying all morning' (PB), a couple of interviewees argued that parents would have said something if they felt that the problems discussed in the media storm applied to their institution: 'if there were any dissatisfaction, parents would address it. But no, I know what I do is okay and I have good contact with the parents and they keep coming with their children' (PD).

Despite this rather positive tone, one might be sceptical as the parents' positive view does not square completely with the reflective and somewhat critical view of the pre-school teachers themselves. In fact, the pre-school teachers themselves were sceptical and looked for reasons why parents were so positive. Some underlined that parents only knew their local crèche, where everything was okay, while others pointed to a sort of false consciousness among parents: 'parents are under pressure and today's parents are not 
good at asking about the pedagogical work we do. It's more the practical stuff - e.g. that a slipper is missing' (PB). Another interviewee phrased her suspicion more clearly: 'perhaps parents don't wish to acknowledge it [potential problems]; if you leave you kids in a crèche you want the best for them. It'll have huge consequences for the parents if they feel they leave their children somewhere that they think isn't okay. And that's why I think they try to find the positive in it' (PF). The interviewees, in other words, suspected that parents were so busy and keen on believing that it was in the best interest of everybody to leave their children in crèches that they held on to this conception and refrained from critical reflection even during a media storm that pinpointed relevant issues.

Our study does not allow us to investigate parents' thoughts, and we cannot conclude if the pre-school teachers' suspicion about the effect of parents' busyness and dependence upon trouble-free care of their children is correct. We leave this for future studies. We can conclude, however, that parents do not intensify the pressure on pre-school teachers to perform during the media storm. In this sense, the media storm was inconsequential at the street level.

\section{Conclusion and discussion}

While existing studies show that media storms do not affect policy formulation, we argue that such storms affect policy implementation. Our pioneering case study supports this theoretical idea. In particular, it suggests that Danish pre-school teachers do not merely reflect on, but also adjust their practice as a consequence of a media storm in order to satisfy their functional preference for doing their job well. Furthermore, our case study suggests that neither reflections, nor adjustments are due to intensified pressure from pre-school teachers' superiors or the target group. We are thus witnessing a direct, rather than an indirect, effect of the media storm at the front-line workers. Our perhaps most interesting finding is that pre-school teachers approach the media storm constructively; rather than shielding themselves by employing coping strategies, they perceive the media storm as an opportunity to figure out whether they could do an (even) better job.

These empirical lessons learned reinforce our central argument that both the political communication and the public administration literature have something to gain by studying media effects at the street level. Our case study also illuminates the benefit of exploring the direct route (the functional and solidary interests of the front-line worker) and the indirect 
routes (the pressure of intermediate management and the target group) of media effects. We do not have the empirical data to draw final conclusions about the media-bureaucracy interaction, but we demonstrate the fruitfulness of further exploration of this uncharted territory.

One way ahead would be to investigate the factors that condition media effects at the street level: First, it would be important to study the moderating effect of proximity. While we studied universal effects in the pre-school sector, we suggest that larger effects would be found locally, for instance among employees in a hospital ward in which insufficient hygiene gives rise to a media storm. Second, the degree of professional discretion varies significantly across the public sector (Vinzant \& Crothers, 1998), and it might matter to the size of the media effect. While our case - we argue - is illustrative for the pre-school sector, it might also be indicative of the wider social sector; at least e.g. elderly care and caring for people with social problems entails ample room for professional judgement. Our case, however, might not be illustrative for the entire public sector; front-line workers characterized by a strong professional ethos (e.g. doctors at hospitals), by adherence to scientific evidence (e.g. engineers in infrastructure offices), or by dense legal regulation (e.g. caseworkers in labour market administrations) might be less susceptible to media storms. Third, the nature of the media storm is likely to condition its effect across all sectors. In our case, the media storm revolves around research findings, which might enhance the effect of the storm because of the scientific nature of the information. In other cases, media storms arise from political disputes, publicity craving news organizations, or implementation failure in isolated instances (e.g. Elmelund-Præstekær \& Wien, 2008). Such storms might dominate the media agenda but only marginally affect front-line workers if they do not recognize the severity of the issue. Finally, to further develop the understanding of the street-level consequences of media storms, it would be important to interview not only front-line workers, but also their intermediate managers, the responsible elected officials, and the target group.

In sum, it is clear that future studies will be able to taker bigger empirical leaps than the present chapter, but they will hopefully benefit greatly from applying the approach suggested in this chapter, i.e. the theoretical marriage of the scientific fields of political communication and public administration. 


\section{References}

Bennett, Lance W. \& Shanto Iyengar (2008). 'A new era of minimal effects? The changing foundations of political communication'.Journal of Communication, $5^{8}(4): 707-731$.

Boydstun, Amber E., Hardy, Anne \& Stefaan Walgrave (2014). 'Two faces of media attention: Media storm vs non-storm coverage'. Political Communication, 31 (4):509-531.

Brehm, John \& Scott Gates (1997). Working, shirking, and sabotage. A bureaucratic response to a democratic public. Ann Arbor, MI: University of Michigan Press.

Carpenter, Daniel P. \& George A. Krause (2012). 'Reputation and public administration'. Public Administration Review, 71 (1):26-32.

Elmelund-Præstekær, Christian \& Charlotte Wien (2008). 'What's the fuss about: The interplay of media hypes and politics'. InternationalJournal of Press/Politics, 13 (3): 247-266.

Eshuis, Jasper \& Erik Hans Klijn (2012). Branding in governance and public management. New York: Routledge.

Galtung, Johan \& Mari Holmboe Ruge (1965). 'The structure of foreign news: The presentation of the Congo, Cuba and Cyprus crises in four Norwegian newspapers'. Journal of International Peace Research, 2 (1): 64-91.

Hjarvard, Stig (2013). The mediatization of culture and society. London: Routledge.

Hood, Christopher (2010). The blame game: Spin, bureaucracy and self-preservation in government. Princeton, NJ: Princeton University Press.

Kaufmann, Geir \& Astrid Kaufmann (2008). Psykologi organisation og ledelse. København: Akademisk ledelse.

Kepplinger, Hans Mathias \& Sonja Glaab (2007). 'Reciprocal effects of negative press reports'. European Journal of Communication, 22 (3): 337-354.

Korthagen, Iris \& Erik-Hans Klijn (2014). 'The mediatization of network governance: The impact of commercialized news and mediatized politics on trust and perceived network performance'. Public Administration, 92 (4): 1054-1074.

Lipsky, Michael (1980). Street-level bureaucracy:Dilemmas of the individual in public service. New York: Russell Sage Foundation.

May, Peter J. \& Søren C. Winter (2009). 'Politicians, managers, and street-level bureaucrats: Influences on policy implementation'.Journal of Public Administration Research \& Theory, 19 (3): 453-476.

Mazzoleni, Gianpietro \& Winfried Schulz (1999). 'Mediatization of politics: A challenge for democracy?' Political Communication, 16 (3): 247-261.

Neuman, W. Russell \& Lauren Guggenheim (2011). 'The evolution of media effects theory: A six-stage model of cumulative research'. Communication Theory, 21 (2): 169-196. 
Nielsen, Vibeke Lehmann (2002). Dialogens Pris. Uformelle spilleregler, ressourceasymmetri og forskelsbehandling i offentligt tilsyn. Århus: Politica.

Nielsen, Vibeke Lehmann (2006). 'Are street-level bureaucrats compelled or enticed to cope?' Public Administration, 84 (4): 861-889.

Potter, James W. (2013). Media effects. Thousand Oaks, CA: Sage Publications.

Riccucci, Norma M. (2005). How management matters: Street-level bureaucrats and welfare reform. Washington, DC: Georgetown University Press.

Sandfort, Jodi R. (2000). 'Moving beyond discretion and outcomes: Examining public management from the front lines of the welfare system'. Journal of Public Administration Research and Theory, 10 (4): 729-756.

Schillemans, Thomas (2012). Mediatization of public services: How organizations adapt to news media. Berlin: Peter Lang.

Schillemans, Thomas \& Sandra Jacobs (2014). 'Between a rock and a hard place: Framing public organizations in the news'. In: Josef Pallas, Lars Strannegård, Stefan Jonsson (eds), Organizations and the media: Organizing in a mediatized world, 147-161. New York: Routledge.

Thorbjornsrud, Kjersti, Figenschou, Tine Ustad \& Øyvind Ihlen (2014). 'Mediatization in public bureaucracies: A typology'. Communications, 39 (1): 3-22.

Trumbo, Craig W (2012). 'The effect of newspaper coverage of influenza on the rate of physician visits for influenza 2002-2008'. Mass Communication and Society, $15(5): 718-738$.

Vasterman, Peter (2005). 'Media-hype: Self-reinforcing news waves, journalistic standards and the construction of social problems'. European Journal of Communication, 20 (5): 508-530.

Vinzant, Janet Coble \& Lane Crothers (1998). Street-level leadership. Discretion and legitimacy in front-line public service. Washington, DC: Gorgetown University Press.

Vliegenthart, Rens \& Stefaan Walgrave (2011). 'When media matter for politics: Partisan moderators of mass media's agenda-setting influence on parliament in Belgium'. Party Politics, 17 (3): 321-342.

Weaver, David, McCombs, Maxwell \& Donald L. Shaw (2004). 'Agenda-setting research: Issues, attributes, and influences'. In: Lynda Lee Kaid (ed.), Handbook of political communication research, 257-281. London: Lawrence Erlbaum Associates.

Wilmar, Maria Wramsten, Ahlborg, Gunnar, Jacobsson, Christian \& Lotta Dellve (2014). 'Healthcare managers in negative media focus: A qualitative study of personification processes and their personal consequences'. BMC Health Services Research, 14 (8).

Winter, Søren (1994). Implementering og effektivitet. Herning: Systime. 


\section{About the authors}

Pernille Carlsson holds a Master's degree in political science. Her main interest is on public administration and management and more specifically on public sector innovation as well as effects of media storms on public administration.

Christian Elmelund-Præstekær holds a PhD in political science and is Head of Department at the Department of Political Science and Public Management, University of Southern Denmark. His primary field of interest is political communication broadly defined and he have studied the nature and effects of media storms as well as parties' campaign communication and agenda-setting hereof. His work has most recently appeared in scientific journals such as the European Political Science Review, European Journal of Communication, Party Politics, and Social Policy \& Administration. 
